\title{
Effect of Pranayama on Pulmonary Functions in Young Healthy Females
}

Dheeraj Jeph $^{1}$, Sanjay Kumar Singhal ${ }^{1}$, Nidhi Gupta ${ }^{1 *}$

${ }^{1}$ Associate Professor, Department of Physiology, SMS Medical College, Gangawal Park, Adarsh Nagar, Jaipur, Rajasthan 302004, India

DOI: $10.36347 /$ sjams.2021.v09i03.009

| Received: 18.02.2021 | Accepted: 02.03.2021 | Published: 05.03.2021

*Corresponding author: Nidhi Gupta

Abstract

Original Research Article

The present study was undertaken to assess the effects of pranayama on pulmonary functions. Sixty healthy young female subjects (age group 18-28 years) were selected. They have to do the selected pranayama practices daily for about half an hour. The observations were recorded by MEDSPIROR, in the form of FVC, FEV-1 and PEFR on day-1, after 4 weeks and 8 weeks of their pranayama practice. There was a significant increase in FVC, FEV-1 and PEFR at the end of 8 weeks.

Keywords: Pranayama FVC, FEV-1, PEFR.

Copyright $\left({ }_{0} 2021\right.$ The Author(s): This is an open-access article distributed under the terms of the Creative Commons Attribution 4.0 International License (CC BY-NC 4.0) which permits unrestricted use, distribution, and reproduction in any medium for non-commercial use provided the original author and source are credited.

\section{INTRODUCTION}

Medical science tries to achieve an optimum physical and mental health of the individual through preventive, curative and promotive aspects. However, for a long time medical professionals have laid much emphasis on the curative aspect and only relatively recently the preventive aspect is also being emphasized. In yogic practice the stress is mainly on the preventive aspect, although some yogic methods are also prescribed for curative purpose as well.

A number of studies have been alone to assess the effect of pranayama on pulmonary functions. Udupa et al., studied the effects of some breathing exercises (pranayama) in normal subject [1]. Nayar et al., documented the effect of yogic exercises on human physical efficiency [2]. Yadav Raj Kumar et al studied the effect of yogic practice on pulmonary functions in young females [3]. In another study by Miles Wales, oxygen consumption during three yoga-breathing patterns were studied [4]. In a related work, Makwana et al., also studied the effect of short term yoga practice on pulmonary function tests [5].

The present study has been done exclusively on young healthy females to add more data in the field of yoga and pulmonary functions.

\section{METHODS}

The study was carried out at the Yoga Therapy and Research Centre (YOGA O.P.D) Department of physiology, SMS hospital, Jaipur.
Total 60 healthy young females volunteered as subjects and their physical characteristics like height, weight and age were recorded (Table-1).

All the subjects performed yoga practice daily for about half an hour (30 min). The yogic schedule consisted of an 'Om' chanting, Pranayama and meditation. The schedule included different pranayama as written below:

\begin{tabular}{|l|l|}
\hline Kapalbhati (kriya) & $2 \mathrm{~min}$ \\
\hline Dheerag-swas-preksha & $5 \mathrm{~min}$ \\
\hline Anulom - vilom & $5 \mathrm{~min}$ \\
\hline Bhramari & $3 \mathrm{~min}$ \\
\hline Meditation & $15 \mathrm{~min}$ \\
\hline Total & $\mathbf{3 0} \mathbf{~ m i n}$ \\
\hline
\end{tabular}

The subjects who became pregnant during the study were excluded. The subjects with diabetes, hypertension and chronic respiratory problems like asthma, tuberculosis were also excluded.

Pulmonary Function Tests (PFT) was recorded by MEDSPIROR-made in India (Chandigarh) - a computerized dry type spirometer. The parameters of PFT included in the study were- FVC (Forced Vital capacity), FEV-1 (Forced Expiratory Volume in $1^{\text {st }}$ second) and PEFR (Peak Expiratory Flow rate). Recording were done on day-1, after 4 weeks and after 8 weeks of pranayama practice. 
Day-1 means the very first day the subjects started yogic practice. For PFT- The subjects were first explained the whole procedure and were demonstrated the same after obtaining their consent, the subjects performed the test in sitting position.

\section{Statistical Analysis}

The results of PFT are presented as Mean \pm S.D. The data were analyzed using students' $t$ ' test. $P$ values $<0.05$ were considered significant.

\section{RESULTS}

The results have been summarized in Table-1. The FVC, FEV-1, and PEFR of all the subjects on day1, 4 weeks and 8 weeks has been given. It is evident that the PFT parameters have higher values at 4 weeks and 8 weeks in comparison to day- 1 values. The $P$ value has been calculated at 4 weeks and 8 weeks in comparison to values on day-1.

Table-1: Physical Characteristics of Subjects

\begin{tabular}{|l|l|l|l|}
\hline & Mean & Median & S.D. \\
\hline Age group (yrs) & 22.8 & 22.7 & 3.62 \\
\hline Height $(\mathrm{cm})$ & 154.2 & 155.0 & 4.85 \\
\hline Weight $(\mathrm{Kgs})$ & 54.8 & 55.0 & 7.5 \\
\hline
\end{tabular}

Table-2: Comparison of Pulmonary Function Tests

\begin{tabular}{|l|l|l|l|}
\hline Duration & $\begin{array}{l}\text { FVC (lit) } \\
\text { Mean } \pm \text { S.D. }\end{array}$ & $\begin{array}{l}\text { FEV-1 (lit) } \\
\text { Mean } \pm \text { S.D. }\end{array}$ & $\begin{array}{l}\text { PEFR(lit/sec) } \\
\text { Mean } \pm \text { S.D. }\end{array}$ \\
\hline Day-1 & $2.018 \pm 0.288$ & $1.988 \pm 0.289$ & $5.10 \pm 1.13$ \\
\hline 4 Weeks & $2.273 \pm 0.275^{*}$ & $2.245 \pm 0.277^{*}$ & $5.34 \pm 1.11^{* *}$ \\
\hline 8 Weeks & $2.542 \pm 0.268^{*}$ & $2.505 \pm 0.266^{*}$ & $5.57 \pm 1.08^{* * *}$ \\
\hline
\end{tabular}

$* \mathbf{P}<\mathbf{0 . 0 0 1} * * \mathbf{P}=\mathbf{N} . \mathbf{S} . * * * \mathbf{P}<\mathbf{0 . 0 5}$

\section{DISCUSSION}

In our study, FVC and FEV-1 were significantly higher at 4 weeks and 8 weeks from day-1 $(\mathrm{P}<0.001)$. However, PEFR is not statistically significant at 4 weeks but value of PEFR is higher at 4 weeks in comparison to day-1. At 8 weeks, PEFR is significantly higher than day-1 $(\mathrm{P}<0.05)$.

Yadav Raj Kumar et al., reported significant increase in FVC, FEV-1 and PEFR after 12 weeks of Yoga training [3].

Makwana et al., reported significant increase in FVC following 10 weeks of yoga training [5] others have recorded similar observations $[2,6]$. The improvement in vital capacity is due in part to increase in development of respiratory musculature incidental to regular practice of yogic exercises [7].

By the yogic practice the respiratory apparatus is emptied and filled more completely and efficiently which is recorded in terms of increased FVC. Similar ventilatory training even in elderly subjects (age 60 to75 yrs) has been shown to improve lung volumes and capacities [8]. Joshi et al., reported significant increase in FVC and PEFR following 6 weeks of pranayama practice [9].

Lung inflation near to total lung capacity is a major physiological stimulus for the release of lung surfactant [10] and prostaglandins into alveolar spaces [11], which increase lung compliance and decrease bronchial smooth muscle tone respectively. The other possible mechanism for improved PFT may be:
1. Cleansing procedures cleans the infective nasal secretion.

2. Increased power of respiratory muscles that is due to the work hypertrophy of the muscles during pranayama and other exercises.

3. Yogic breathing exercises train practitioners to use the diaphragmatic and abdominal muscles more efficiently thereby emptying and filling the respiratory apparatus more efficiently and completely [5]

4. Yoga, with its calming effect on the mind can reduce and release emotional stresses, thereby with drawing the branchoconstrictor effect.

Thus, practice of yogic exercises seems to be beneficial for respiratory efficiency. A number of studies have been done to show the beneficial effects of yoga on asthmatic patients $[12,13]$.

Bera et al., have studied recovery from stress by yogic relaxation posture in their work [14].

In conclusion, it can be stated that pranayama is beneficial for the better maintenance of body functions, particularly pulmonary functions, even in normal healthy persons with significant increase in FVC, FEV-1 and PEFR at the end of 8 weeks of pranayama practice in young healthy females.

\section{REFERENCES}

1. Udupa KN, singh RH, settiwar RM. Studies on the effect of some yogic breathing exercises 
(pranayama) in normal persons. Indian J Med Res. 1975; 63: 1062-1065.

2. Nayar HS, Mathur RM, Kumar RS. Effects of yogic exercises on human physical efficiency. Indian J Med Res. 1975; 63: 1369-1376.

3. Yadav RK, Das S. Studies on the effect of yogic practice on pulmonary functions in young females. Indian J physiol pharmacol. 2001; 45(4): 493-496.

4. Miles WR. Oxygen consumption during three yoga breathing pattern. J Appl Physiol. 1964; 19: 75-82.

5. Makwana K, Khirwadkar B, Gupta HC. Effect of short-term yoga practice on ventilator function tests. Indian J Physiol Pharmacol. 1988; 32: 202208.

6. Udupa KN, Singh RH, Settiwar RM. A comparative study on the effects of some individual yogic practice in normal persons. Indian J Med Res. 1975; 63: 1066-1071.

7. Bhole MV. Treatment of bronchial asthma. Yoga Mimansa. 1967; 9: 33.

8. Belman MJ, Gaesser GA. Ventilatory muscles training in the elderly. J Appl Physiol. 1983; 64: 899-905.
9. Joshi LN, Joshi VD, Gokhale LV. Effect of short term 'Pranayama' practice on breathing rate and venilatory functions of lungs. Indian $\mathrm{J}$ Physiol Pharmacol. 1992; 36: 105-108.

10. Hildebran J, Georke J, Clements JA. Surfactant release in exercised rat lungs stimulated by air inflation. J Appl Physiol. 1981; 51: 905-910.

11. Smith AP. Prostaglandins and respiratory system, Prostaglandins: Physiological, Pharmacological and pathological aspects, edited by S.M.M. Karim. 1976; 83-102.

12. Khanam AA, Sachdeva U, Guleria R, Deepak KK, study of Pulmonary and autonomic functions of asthma patients after yoga training. Indian $\mathrm{J}$ Physiol Pharmacol. 1966; 40: 318-324.

13. Singh V, Wisniewski A, Britton J, Tatters field A. Effect of yoga breathing exercises (Pranayama) on airway reactivity in subjects with asthma. Lancet. 1990; 335(8702): 1381-1383.

14. Bera TK, Gore MM, Oak JP. Recovery from stress in two different postures and in Shavasana- a yogic relaxation posture. Indian $\mathbf{J}$ Physiol Pharmacol. 1998; 42: 473-478. 